\title{
Trajectories of Self-Evaluation Bias in Primary and Secondary School: Parental Antecedents and Academic Consequences
}

\begin{abstract}
Using a longitudinal approach spanning nine years of children's formal education, this study investigated the developmental trajectories of self-evaluation bias of academic competence. The study also examined how parenting styles were associated with the trajectories of bias in mid-primary school, and how those trajectories predicted academic outcomes at the end of secondary school and the beginning of college. A total of 711 children in $4^{\text {th }}$ and $5^{\text {th }}$ grades (mean age $=10.71$ years old; 358 girls) participated in this study. Using a latent class growth modeling framework, results indicated that children can be classified in three latent growth trajectories of self-evaluation bias: the optimistic, realistic and pessimistic trajectories. These trajectories differed in their initial status of bias and also in their development over time. Children's adherence to a specific trajectory was associated with parenting variables in childhood. Finally, the optimistic, realistic, or pessimistic trajectories distinctively predicted achievement and persistence.
\end{abstract}

Keywords: Academic Self-Perception Bias; Latent Trajectories; Childhood and Adolescence; Parenting Styles; Achievement; Persistence. 
Trajectories of Self-Evaluation Bias in Primary and Secondary School: Parental Antecedents and Academic Consequences

Are there distinct developmental trajectories of self-evaluation bias of academic competence? Self-evaluation bias of academic competence (SEB) has been conceptualized as the discrepancy between children's perceptions of competence at school and assessments taken from more objective measures of academic competence (for example, taken from IQ or scholastic ability tests; Bouffard, Vezeau, Roy, \& Lengelé, 2011; Cole, Martin, Peeke, Seroczynski, \& Fier, 1999; Gresham, Lane, MacMillan, Bocian, \& Ward, 2000). Biases in self-evaluation of competence can broadly be categorized into three groups: positive (optimistic), unbiased (realistic), and negative (pessimistic). Depending on the direction of the perception of bias, children are more or less likely to be involved in their school learning and consequently to take active steps when they learn. However, research on the trajectories of SEB in childhood and adolescence is scarce. The lack of research in this area lays mainly in an absence of information on the predictors of SEB, the paucity of multiple informers to evaluate the results, the use of arbitrary cut-off scores to separate biased and unbiased children, and the absence of large samples to evaluate the trajectories of SEB over long periods of time. Few empirical studies have documented the factors that may be linked to an overly positive or negative self-evaluation of children's own competence at school (Bouffard et al., 2011; Cole et al., 1999). In addition, no consensus exists in the benefit of being either realistic or optimistic in one's own self-evaluation of competence. Clear associations have been found between holding a negative bias in selfevaluation of academic competence in childhood, and poor motivation, reduced self-image, lack of confidence, depression, and lower levels of achievement (Bouffard, Boisvert, \& Vezeau, 2002; Cole et al., 1999; Gresham et al., 2000). Given the poor adjustment negatively biased 
children display, and the lack of consensus regarding the benefits of being either unbiased or positively biased (Colvin, Block, \& Funder, 1995; Taylor \& Brown, 1988), further research in this area is needed to understand the correlates, longitudinal trajectories, and consequences of school-related SEB.

Discrepancies between children's self-evaluation of their own competence and objective cognitive abilities may be in part rooted in the child's immediate social environment, such as parental behavior, that shapes these evaluations (Côté, Bouffard, \& Vezeau, 2014). Thus, a critical component in understanding the effect of SEB is to examine how parenting can influence the development of self-evaluation bias, how this bias develops over a long period of time, and finally how SEB can predict persistence and achievement in the long run. In the present study, we examined three aspects of the development of self-evaluation bias. First, we longitudinally assessed the types (negatively or positively biased, or unbiased) and trajectories of bias. Second, we evaluated parental influences on those trajectories. Finally, we examined the consequences of having self-evaluations biases at the end of an important school cycle: the end of secondary school. Based on Bandura's (1986) self-efficacy theory framework, we assumed that children's trajectories of SEB should be influenced by significant social agents, such as parents, and should also be an important predictor of their academic success at school.

\section{Development of Self-Evaluation Biases of Academic Competence}

Positive self-evaluations of academic competence are widespread among children at the beginning of primary school, and may be part of a common developmental path (Bouffard, Markovits, Vezeau, Boisvert, \& Dumas, 1998; Wigfield \& Eccles, 2000). These positive competence beliefs decrease throughout elementary school (Eccles, Wigfield, Harold, \& Blumenfeld, 1993; Jacobs, Lanza, Osgood, Eccles, \& Wigfield, 2002). Further, children 
gradually develop a better understanding of the similarities and differences between the concepts of ability, effort and performance, across domains (Bong, Cho, Ahn, \& Kim, 2012). Children also become better at making social comparisons and at integrating past successes and failures, leading them to develop more realistic self-evaluations of their own competence (Boissicat, Pansu, Bouffard, \& Cottin, 2012; Bong \& Clark, 1999; Bouffard et al., 1998). However, positive biases remain pervasive in a subgroup of children whereas other children come to develop a more negative view of themselves.

The developmental trajectories of SEB are less clear from the end of primary school through secondary school. Cole et al. (1999) have found distinct trends in SEB for boys and girls. Whereas boys tended to increasingly overestimate their academic competence over the course of three years, girls increasingly underestimated their competence. Bouffard, Vezeau, Roy, and Lengelé (2011) examined five developmental trajectories of SEB. They have found that, whereas the optimistic and realistic trajectories remained mostly stable between the ages of nine and 14 years old, some pessimistic children became even more pessimistic over time, and the negative bias of a minority of children decreased to become more realistic over time. In sum, it appears that the trajectories of SEB are not fixed in childhood and adolescence.

\section{Self-Evaluation Bias of Competence and Academic Outcomes}

The optimistic, realistic, and pessimistic classes of SEB have been shown to be related to a wide range of social and psychological consequences in childhood (Gramzow, Elliot, Asher, \& McGregor, 2003; Gresham et al., 2000). According to the theory of positive illusions (Taylor \& Brown, 1988), holding moderately positive (optimistic) views of oneself leads to adaptive psychological consequences. In spite of this, significant disagreements still exist about the benefits of holding an enhanced bias of academic competence in relation to academic 
functioning, including interest, achievement, and persistence. When positive consequences have been found, they were related to higher mean-levels of academic achievement and motivation (Bouffard et al., 2011; Côté et al., 2014; Dupeyrat, Escribe, Huet, \& Régner, 2011; Kurman, 2006; Wright, 2000). However, negative links between positive illusions and achievement in reading and mathematics have also been observed (Gresham et al., 2000). Finally, some studies have revealed mixed effects of positive biases on academic adjustment measures (Gonida \& Leondari, 2011; Gramzow, Elliot, Asher, \& McGregor, 2003). For instance, Gonida \& Leondari (2011) have found that positively biased pupils had higher mean-level scores on interest in maths and language, but did not significantly differ from the other groups on the persistence measures. Gresham and colleagues (2000), have hinted that an overly positive SEB in childhood may hinder academic adjustment in the long run. The researchers have suggested that optimistic pupils may be cognitively immature, or that this optimism may have a self-protective role against repeated negative feedback. According to this view, a positive SEB may be volatile, and optimistic pupils may regain a realistic view of their competence later in childhood, when they reach the appropriate level of maturity, or when they are exposed to increasingly complex knowledge. Furthermore, these children may be less likely to persist when their optimistic selfviews are challenged by the demands of secondary school. Longitudinal research on the longterms effects of positive SEB on academic adjustment (e.g., Bouffard et al., 2011; Cole et al., 1999) has not reached a definitive conclusion. Bouffard and colleagues (2011) have found that positively biased children still outperform other pupils in the language and math domains at age 14 , but nothing is known about the effects of the trajectories of SEB beyond the first years of secondary school.

Does a realistic view of one's own competence lead to adaptive academic adjustment? 
According to Colvin, Block, and Funder's (1995) realistic knowledge theory, a realistic understanding of oneself leads to better psychological functioning. Empirical research is scarce on the relations between realistic self-views and academic functioning in childhood and adolescence. Gonida and Leondari (2011) and others (e.g., Bouffard et al., 2011) have found that realistic pupils scored significantly lower than optimistic pupils in terms of academic outcomes, including achievement and persistence. Using a sample of university students, Wright (2000) has observed that realistic students were less accurate in their estimation of their final grade point average than the positively biased students. In sum, the results of these studies are inconclusive regarding the benefits of having a realistic view of one's academic self.

Research has mostly agreed that holding overly negative self-perceptions is detrimental for academic adjustment, as it adversely affects pupils' motivation and engagement (Bouffard et al., 2002, 2011; Gonida \& Leondari, 2011). At equivalent achievement levels, pessimistic children also display lower mean levels of satisfaction with their results than other pupils (Narciss, Koerndle, \& Dresel, 2011).

In sum, although a consensus exists on the negative impact on holding a pessimistic self view, empirical and theoretical evidence has been inconclusive regarding the effects of having positive biases, or being realistic about one's own competence at school.

\section{Parental Influences on Self-Evaluation Biases}

Children's interactions with significant social agents, such as parents, are important sources of information that they use to evaluate their own competence (Bandura, 1986, 1997). Several parenting factors, such as parental self-efficacy and parenting styles, can influence the trajectories of bias in children's self-evaluation of academic competence. 
Parental self-efficacy beliefs refer to the parents' expectations about the degree to which they are able to perform effectively to exert a positive influence on the development of their children (Ardelt \& Eccles, 2001; Coleman \& Karraker, 1998; Steca, Bassi, Caprara, \& Fave, 2011). Parents who have higher parenting self-efficacy beliefs tend to give more accurate feedback to their children regarding their successes and failure (Jones \& Prinz, 2005), and are more actively involved with their children (Bandura, Barbaranelli, Caprara, \& Pastorelli, 1996; Ice \& Hoover-Dempsey, 2011; Jones \& Prinz, 2005; Steca et al., 2011). Related to parental selfefficacy, Côté and colleagues (2014) have found that the availability of parental support was linked to a positive bias in self-evaluation and to a more adaptive academic school functioning. In sum, parental self-efficacy seems to lead to the preservation of an optimistic SEB in children or to the development of unbiased self-evaluations, but no research to date has empirically investigated this hypothesis.

Parenting styles may be another source of influence on children's development of a particular SEB trajectory (for reviews of parenting styles and academic functioning, see Pinquart, 2015; Spera, 2005). Empirical evidence suggests that parenting style is also associated with adolescents' psychological functioning (Brand, Hatzinger, Beck, \& Holsboer-Trachsler, 2009; Gonzalez, Doan Holbein, \& Quilter, 2002; Hart, Newell, \& Olsen, 2003; Hartman et al., 2015; Wolfradt, Hempel, \& Miles, 2003). Various typologies exist regarding parenting styles. Among those, the distinction between authoritative and authoritarian styles (Baumrind, 1971) remain widely used (Pinquart, 2015; Spera, 2005). While authoritative parents support autonomy, provide a clear structure to children, and rely on explanations for rules, authoritarian parents base their parental behavior on authority (Baumrind, 1971, 1991; Spera, 2005). Past research has revealed that children raised in a more authoritative environment have clear developmental 
advantages, such as higher levels of perceived competence at school, and greater task engagement (Aunola, Stattin, \& Nurmi, 2000; Dornbusch, Ritter, Leiderman, Roberts, \& Fraleigh, 1987; Hart et al., 2003; Pong, Johnston, \& Chen, 2010). The authoritarian parenting style has been shown to foster feelings of control and devaluation in children (Gonzalez et al., 2002; Masud, Thurasamy, \& Ahmad, 2015). In addition, some authors report that socioeconomic and cultural parental variables, especially education, ethnicity and annual income, influence parenting styles (Coleman \& Karraker, 2000), children's perceptions of competence (Kim, 2014), and academic performance (Choi, Chang, Kim, \& Reio, 2015; Stull, 2013; Wiederkehr, Darnon, Chazal, Guimond, \& Martinot, 2015). It is also suggested that, in Western cultures, an authoritative parenting style is in most cases associated with better school adjustment (Spera, 2005).

Taken together, research on self evaluation biases of academic competence has provided good reasons to believe that the trajectories of SEB are not fixed in childhood, that these trajectories are influenced by parenting factors, and that they uniquely predict academic achievement and persistence in the long run, but few studies have investigated these possibilities.

\section{Overview of the Present Research}

The overarching aim of the current study was to gain a deeper understanding of the correlates and consequences of the trajectories of SEB in childhood and adolescence. The present research had three specific objectives. The first objective was to identify the presence of multiple developmental trajectories of bias in self-evaluation of competence. More specifically, in line with past research, we made the assumption that the vast majority of children hold either an Optimistic, Realistic, or Pessimistic view of their academic selves (Bouffard et al., 2011; Cole et al., 1999). We used a person-oriented approach to examine this objective. Traditional 
longitudinal data analysis approaches assume that individuals come from a homogenous population. By contrast, the aim of person-oriented analytical methods is to describe the links among individuals by classifying them into distinct categories based on their individual patterns of answer, not assuming that the population is homogenous (Jung \& Wickrama, 2008). With person-oriented approaches, the response patterns of students within a category are expected to be more similar than response patterns between categories. The person-oriented approach has the added benefit of allowing us to examine the categories of students as they would naturally occur in the population instead of splitting them using arbitrary cut-off scores (e.g., the mean).

The second objective was to assess whether the different trajectories are associated with parental covariates at baseline. Despite the apparent support for the link between children's perceptions of competence, and their parents' self-efficacy beliefs and parenting styles (Aunola et al., 2000; Fan \& Williams, 2010), no study to date has examined whether these parental factors are involved in the development of children's academic SEB. Because gender was found to affect the trajectories of SEB in past research (Cole et al., 1999), gender was also added as a covariate.

The third objective was to examine whether the trajectories of SEB can predict two aspects of children's academic functioning at the end of secondary school and first year of college: academic achievement and persistence. In terms of academic achievement, past research suggests that optimistic pupils tend to perform better than other groups in the middle of secondary school, that pessimistic pupils tend to perform worse than any other group, and that realistic students might fall in between (Bouffard et al., 2011; Gonida \& Leondari, 2011). However, little is known about the long-term effects of self-evaluation biases on academic achievement and persistence beyond age 14 . 
To achieve these objectives, we performed a longitudinal study that followed children from the middle of their primary school through to their first year of college. We assessed not only children's perceptions of their own academic competence, but also used an objective measure of school ability, as well as measures taken from parents and teachers.

\section{Method}

\section{Participants and Procedure}

The current study was part of a larger 9-year longitudinal study, conducted between 2005 and 2013, on academic functioning of children in regular school classes from the Greater Montreal area, in Canada. All 13 primary schools in the designed area were invited to participate. The schools whose head of school and teachers responsible for the 4 th and 5 th grades agreed to participate during regular hours were invited to further take part in the longitudinal study. Therefore, participating children and their parents and teachers were recruited from nine public schools located in either middle (7) or low (2) socio-economic environments (assessed using the School Disadvantage Index, 2005). This resulted in a sample of 746 children who were in their $4^{\text {th }}$ and $5^{\text {th }}$ grades at T-1, in 2005. All teachers, parents, and children completed a consent form approved by the University ethics committee.

Only children who themselves had completed all the relevant measures at T-1 and T-2 were kept for further analysis. This resulted in 711 children being included in the present study ( $n=354$ in 4th Grade, and $n=355$ in 5th Grade). These children were aged on average 10.71 years old at T-1 $(S D=.65)$, and were almost equally distributed between boys $(n=353)$ and girls $(n=358)$. The sample was relatively homogenous. The vast majority of parents reported being French Canadian (90.7\%), $8 \%$ refused to answer, and $1.3 \%$ were either Haitian or Asian. Among parents, $24.3 \%$ of fathers and $22.5 \%$ of mothers had a university degree, $24.6 \%$ of 
fathers and $36 \%$ of mothers a college diploma, $30.1 \%$ of fathers and $23.6 \%$ of mothers had a high school diploma, and $21 \%$ of fathers and $17.9 \%$ of mothers had a professional degree.

Using the sample of 711 participants retained for further examination, we conducted attrition analyses on the outcome measures. A series of ANOVAs and Chi-Square analyses performed with children who did not complete the last measure of SEB at T-7 $(n=234)$, as compared with children who completed T-7 $(n=497)$, revealed that children who did and did not complete T-7 were similar in their self-perception of bias at baseline, $F(1,709)=1.20, p=.27$, and in their perceptions of authoritarian and authoritative parenting styles, $F(1,709)=0.77, p=$ .38 , and $F(1,709)=0.02, p=.80$, respectively. Children who did not complete $\mathrm{T}-7$ had parents who scored lower on parental self-efficacy, $F(1,522)=9.68, p=.002$, and were more likely to be boys, $\left.\chi_{(1)}^{2}=7.40, p=.007\right)$. To measure objective persistence, all students were reached by phone at the beginning of College (equivalent to $12^{\text {th }}$ grade in the USA or the first year of Sixth Form in the UK). Out of the 711 children who were included in the present study, we were able to obtain data on persistence via phone interviews for 341 of them. Attrition analysis showed that students who were reached did not differ from those who could not be interviewed on any of the covariates. Therefore, missing values on the self-evaluation bias and the academic functioning variables were accounted for using full information maximum likelihood.

\section{Measures}

Children's Measures. Gender $($ males $=0$, females $=1$ ) was recorded at T-1. Apart from the scholastic ability measure, children responded to the measures using a Likert-type scale ranging from 1 (not at all) to 4 (completely) that indicated to what extent they felt similar to a fictitious pupil described in each of the statements. 
Scholastic Ability. The French version of the Otis-Lennon Mental Ability Test (see Bouffard et al., 2011) was used at T-1 to measure scholastic ability. The children's chronological age serves to transform their total number of correct responses into indices of School Ability Index (in this study $M=102.66, S D=10.68$ ). Previous studies revealed that children's scores on the School Ability Index were very stable over a five-year period (between years correlations ranged from $r=.78$ to $r=.83$; Bouffard, Roy, \& Vezeau, 2005; Bouffard et al., 2011).

Furthermore, research has shown that mental ability remains remarkably stable over time, with a correlation of $r=.63$ between results of mental ability tests measured 66 years apart (at 11 years old and again at 77 years old; Deary, Whalley, Lemmon, Crawford, \& Starr, 2000). Because of the demonstrated longitudinal stability of mental ability measures, it was deemed unnecessary to assess children on their scholastic ability every year.

Perceived academic competence. This measure was used from T- 2 to T-7, using the five statements of the Perceived Competence Scale for Children (Harter, 1982). An example statement is: "This pupil thinks that she or he is good at school." Alpha reliability for this scale in the present study ranged from $\alpha=.73$ to $\alpha=.84$ across years. Means ranged from 2.93 (T-5, $S D=0.60)$ to $3.07(\mathrm{~T}-2, S D=0.62)$, and correlations between adjacent time points ranged from $r$ $=.53$ to $r=.69$.

Parenting styles. Perceptions of authoritarian (six items, e.g., "This pupil has parents who want him or her to obey without discussion", $\alpha=.80$ ), and authoritative (four items, e.g., "This pupil has parents who give him or her reasons why rules should be followed", $\alpha=.75$ ) parenting styles at T-2 were reported by children using items taken from the Parenting Styles and Dimensions Questionnaire by Robinson, Mandleco, Olsen, \& Hart (1995). The mean scores for 
the parenting style scales were as follows: authoritative $M=3.27, S D=0.66$, authoritarian $M=$ $2.08, S D=.71$.

Persistence measures. Persistence was assessed using three indicators: attitudes towards dropout at T-7, highest academic degree sought at T-7, and actual dropout at T-8 (2011, for the $5^{\text {th }}$ Grade cohort) and T-9 (2012 for the $4^{\text {th }}$ Grade cohort).

Attitudes towards dropout refers to students' feeling that schooling has no value and school learning is not meaningful to them (six items, "This student will feel better when s/he drops out of school") taken from Galand (2001). The Cronbach's reliability score for the present study is $\alpha=.81 ; M=1.84, S D=.64$. A higher score indicates more positive attitudes.

Highest academic degree sought. This item was measured by asking children which was the highest academic degree they expected to gain between Secondary School (coded 1), College (CEGEP, equivalent to $12^{\text {th }}$ grade in the USA or Sixth Form in the UK, coded 2), and University (coded 3).

Objective dropout. Telephone interviews were set to reach all students after the end of secondary school (T-8 and T-9). During this interview, children were asked questions about their persistence at school. Those who persisted until at least the end of secondary school were coded one (1) and those who dropped out were coded zero (0). Of those who were reached $(N=341)$, $18 \%$ of children dropped out of school and $82 \%$ persisted. These data on persistence are in line with the public data available on dropout rates in the Province of Quebec, Canada.

\section{Parental measure.}

Parental self-efficacy. Parental self-efficacy taken from the parents themselves was assessed at T-2. This measure comprised six items measured on a 5-point Likert -scale adapted from Hoover-Dempsey, Bassler, and Brissie's (1992) study that relate specifically to parents' 
beliefs of efficacy in helping their child succeed at school through their involvement ("I know how to help my child do well in school."). Cronbach's alpha for the present study was $\alpha=.84 ; M$ $=4.82, S D=0.66$

\section{Teachers' measure.}

Achievement. At T-7, one teacher per student was asked to rate, on a 6-point Likert scale ranging from 1 (very low) to 6 (outstanding; $M=3.64, S D=1.34$ ), how they judged students' school performance in general in comparison with that of the other students in the class. In the Quebec educational system, there is a designated reference teacher for a group of students, who also provides teaching to these students. This teacher usually delivers teaching in the core subjects and has the greatest amount of contact time with students. This teacher has provided the measure of academic achievement reported here. The correlation coefficient between measures of achievement reported by teachers and self-reported by students was of $r=.88$ for the present sample.

\section{Analytic Strategy}

Self-evaluation bias of academic competence. SEB is described as the discrepancy between children's ability at school as reflected in standardized scholastic ability test scores, compared with perceived competence. In line with previous research (Bouffard et al., 2011; Cole et al., 1999; Côté et al., 2014), the scores on perceived competence measured each year were regressed on the scores of scholastic ability to obtain a measure of self-evaluation bias. The standardized residual scores of these regressions were used to assess children's self-evaluation biases at T-2 to T-7. Correlation coefficients between scholastic ability and perceptions of competence ranged between $r=.27$ (T-5) and $r=.40$ (T-3), and were consistent with those reported in past research (Cole et al., 1999). 
Latent class growth analysis. The three specific aims of the study were addressed using a latent class growth analysis modeling approach (LCGM; Jung \& Wickrama, 2008; Muthén, 2002). With LCGM, we first examined the presence of longitudinal latent classes (or growth trajectories) of pupils who shared a common initial level of bias in academic competence, as well as a similar pattern of change over six years. Second, we tested how gender and parenting styles were related to these growth trajectories. Third, we examined whether the different growth trajectories can predict achievement and persistence at the end of secondary school and the beginning of college. In order to examine the growth trajectories, we followed the steps suggested by Jung \& Wickrama (2008), described in Appendix 1 (Online Supplementary Material).

The main analyses were conducted with the Mplus software version 7.3 (Muthén \& Muthén, 2010-2014). In order to find the number of classes that best fit the data, we estimated unconditional LCGMs with various number of classes (in our case, from two to five classes, Jung \& Wickrama, 2008). We then compared model fit information of the different models using several criteria: Bayesian Information Criterion (BIC), Sample-Size Adjusted BIC (SSABIC), Lo-Mendell-Rubin Likelihood Ratio Test (LMR LRT), Vuong Lo-Mendell-Rubin Likelihood LRT (VLMR LRT), Entropy, and Posterior Probability of Class Membership. A better model is indicated by lower AIC, BIC and, SSABIC, significant p-values for LMR LRT and BLRT, and an Entropy as well as the diagonals of the Posterior Probability closer to one. Theoretical usefulness is also assessed by comparing the number of classes found in our data to those found in the literature.

\section{Results}


Repeated-measures analyses of variance showed no gender differences in the six SEB variables. Table 1 displays the correlation coefficients between the variables included in this study. Stability over time between the adjacent time-points of the SEB measures varied between $r=.46$ and $r=.66$. In a nutshell, Table 1 also reveals that most of the relations between SEB and the parenting variables were significant, except for the Authoritarian parenting style. Even stronger links were found between the measures of SEB and academic outcomes.

\section{Defining the Latent Trajectory Classes}

Preliminary analyses of latent growth models (Jung \& Wickrama, 2008), and cohort effects are presented in Appendix 2 (Online Supplementary Material). In summary, we retained a longitudinal model with a quadratic shape, and did not find cohort effects. Therefore, we further analyzed the data with the two cohorts combined.

We determined the number of homogenous latent classes using model fit information. The results of the LCGMs with two, three, four, and five classes are displayed in Table 2. A closer look at the results revealed that a LCGM with three latent growth trajectories best fit the data on Entropy, LMR LRT, and VLR LRT, whilst providing a good fit for posterior probabilities of membership. AIC, BIC, and SSA BIC denoted that the four and five classes solutions were also acceptable, although a review of the intercept and slope parameters showed that these solutions consisted of minor deviations of the Pessimistic class, or did not contain enough children to ensure substantive usefulness. Therefore we retained an unconditional quadratic LCGM with three latent classes. Fit information for this model is presented in Table 2. The developmental trajectories of SEB are depicted in Figure 1. Values on the SEB measures represent standardized scores; therefore an intercept that significantly deviates from zero represents a bias in self-evaluation. The higher growth trajectory presented in Figure 1 (plain 
line) represents $27.9 \%$ of the pupils who significantly over-evaluated their academic competence at baseline (Intercept: $M=0.58, p<.001$ ) as compared with what their cognitive ability alone would predict, and this positive evaluation bias significantly increased over time (Linear slope: $M=0.21, p<.001$; Quadratic slope: $M=-0.03, p=.002$ ), and was named the Optimistic trajectory. The dashed line represents $55.4 \%$ of pupils who realistically evaluated their competence at baseline (Intercept: $M=-0.03, p=.76$ ) and who stayed comparatively unbiased over the course of the study (Linear slope: $M=-0.04, p=.29$; Quadratic slope: $M=$ $0.004, p=.56$ ), and was named the Realistic group. Finally, the dotted-dashed line represents a class of pupils (16.7\% of the sample) with an intercept that was significantly lower than average at baseline (Intercept: $M=-0.95, p<.001$ ), and whose bias became significantly more negative over time (Linear slope: $M=-0.31, p=.003$; Quadratic slope: $M=0.05, p=.006$ ). Therefore, this trajectory was labeled the Pessimistic trajectory.

We performed a univariate ANOVA to examine whether children in the Optimistic, Realistic, and Pessimistic latent trajectory classes differed in their mean levels of cognitive ability at baseline. Results revealed that children had similar levels of school ability (Optimistic $M=102.64$, Realistic $M=103.17$, and Pessimistic $M=101.18, F(2,708)=1.56, p=.21)$.

\section{Parental Covariates of the Distinct Trajectory Classes}

The results of the conditional LCGM, with gender and parenting styles predicting memberships of the Optimistic, Realistic, and Pessimistic latent growth trajectories are presented in Table 3. The model fit information is as follows: $\mathrm{AIC}=13687 ; \mathrm{BIC}=13865$; SSA BIC $=$ 13742. The addition of the covariates did not significantly change the intercepts and slopes of the trajectories. Table 3 reveals that gender was not related to the latent trajectory classes. Parental self-efficacy and the authoritative parenting style were significant predictors of class 
membership. Parents with higher scores on self-efficacy and authoritative parenting were more likely to have children who belong to the Optimistic and Realistic trajectories of bias as compared with the Pessimistic trajectory. No significant effects were found with regards to authoritarian parenting.

A follow-up analysis with mothers and fathers' education levels included as a covariate in the present model indicated that the addition of those variables did not affect the number or trajectories of bias and did not significantly predict the latent growth trajectories, $B<[.30], p>$ $.16, \mathrm{AIC}=15424 ; \mathrm{BIC}=15680 ; \mathrm{SSA} \mathrm{BIC}=15502$.

\section{Academic Outcomes of the Latent Trajectory Classes}

The model fit information for this model is as follows: $\mathrm{AIC}=12397 ; \mathrm{BIC}=12512$; SSA $\mathrm{BIC}=12432$. This model controls for gender, and parental variables, described in the previous section.

Academic achievement. Table 4 presents the estimates for distinct trajectories in the achievement and persistence measures of academic outcomes. Results showed significant differences in teacher-rated achievement between students from the three trajectory classes, $F(2$, 708) $=59.51, p<.001, \omega^{2}=.14$. All simple contrasts between pairs of trajectories were also significant at $p<.001$. Teachers rated the achievement of the Optimistic class of students as significantly higher than both the Realistic $\left(\eta^{2}=.03\right)$, and the Pessimistic $\left(\eta^{2}=.14\right)$ classes, and teachers rated the achievement of the Realistic class of pupils as significantly higher than the Pessimistic class $\left(\eta^{2}=.04\right)$.

Persistence. We observed between-classes mean differences with regards to attitudes towards dropout (see Table 4$), F(2,708)=183.87, p<.001, \omega^{2}=.34$, with all contrasts being significant at $p<.001$. The Optimistic class had significantly fewer positive attitudes towards 
dropout as compared with the Realistic $\left(\eta^{2}=.02\right)$, and Pessimistic classes $\left(\eta^{2}=.32\right)$. The Realistic class also had fewer positive attitudes towards dropout compared with the Pessimistic class $\left(\eta^{2}=\right.$ $.17)$.

The second section of Table 4 displays the estimated proportions for the Optimistic, Realistic, and Pessimistic trajectory classes for the persistence variables measured at the end of Secondary School (T-7) and the beginning of college (T-8 and T-9). In terms of the highest academic degree sought, Table 4 reveals that a majority of Optimistic and Realistic children sought university as their highest degree, whereas Pessimistic children were almost evenly split between secondary school, college and university as their pursued highest level of educational attainment. The Optimistic pupils were $7.91(S E O R 2.83, p=.005)$ times more likely than the Pessimistic class, and 3.08 (SE OR $=0.91, p=.001$ ) times more likely than the Realistic class to want obtain a university diploma as compared to only secondary school, whereas the Realistic children were $2.57(S E O R=0.84, p=.002)$ times more likely than the Pessimistic class of children to want to obtain a university degree, as compared to a secondary school diploma only. With regards to college, results revealed no difference between the Optimistic class and the other classes. However, the odds of the Realistic class of children wanting to go to college were 2.97 $(S E O R=1.16, p=.01)$ times those of the Pessimistic class, as compared with going to secondary school only.

Finally, as seen in the last section of Table 4 the proportion of pupils who dropped out from secondary school increased between trajectory classes from $12 \%$ in the Optimistic group to reach $29 \%$ in the Pessimistic group. The Optimistic pupils were 3.12 (SE OR 1.54, $p=.04$ ) times more likely than the Pessimistic class, and 1.65 ( $S E O R=0.75, p=.03)$ times more likely than the Realistic class to have finished secondary school. Realistic students were 1.89 (SE OR= 
$.89, p=.03$ ) times more likely than the Pessimistic students to have persisted until the end of secondary school.

\section{Discussion}

This is one of the first studies to offer evidence supporting the existence of multiple growth trajectories of self-evaluation bias of academic competence, paired with an examination of parental covariates and academic outcomes. We used children's self-reported perceptions of academic competence and an external measure of academic ability to assess SEB. We obtained three distinct trajectories of SEB and children did not differ in their cognitive ability between the trajectories. The Optimistic trajectory consisted of positively biased pupils at baseline who became more positively biased over six years. The Realistic trajectory included mostly unbiased pupils who remained stable over time. The Pessimistic trajectory comprised negatively biased pupils who became even more negatively biased over the course of the study. The three trajectories found in this study confirm the theoretical and empirical assumptions that most pupils can intrinsically be categorized as positively biased, negatively biased, or unbiased towards their own competence at school (Bouffard et al., 2011; Cole et al., 1999; Connell \& Ilardi, 1987). These results add to previous research as it shows that, if a bias is present in the middle of primary school, this bias tends to increase until the end of high school. In addition, our results reveal that pupils' inclusion in one of the trajectories of SEB can be predicted by positive parenting, and can predict academic achievement and persistence.

\section{The Roles of Parents in Shaping Children's Self-Evaluation Biases}

With regards to the predictors of the trajectories, contrary to Cole et al. (1999), boys and girls seemed to hold similar trajectories of bias in the present research. Among the parental variables, parental self-efficacy was particularly important for predicting pupils' membership in 
the trajectories of SEB. Higher parental self-efficacy - evaluated by the parents themselves increased pupils' likelihood of belonging to the Optimistic trajectory. This result confirms that parents who have high levels of self-efficacy and academic aspirations for their children promote positive self-efficacy beliefs, regardless of their children's actual academic ability (Bandura et al., 1996). In terms of parenting styles, the authoritarian style was unrelated to the trajectories of SEB in the present study. However, children who viewed their parents as authoritative were significantly more likely to belong to the Optimistic trajectory group. Past research has demonstrated the persistent benefit of having authoritative caregivers, both in terms of psychological adjustment and competence beliefs (Steinberg, Lamborn, Darling, Mounts, \& Dornbusch, 1994). Given the advantages that Optimistic children have in their academic functioning, the finding that children who come from authoritative families are about three times more likely to have an Optimistic rather than a Pessimistic developmental trajectory of SEB is of great importance.

In our research, parental self-efficacy seems particularly important for predicting pupils' trajectories of self-evaluation bias. Higher parental self-efficacy increased pupils' likelihood of membership in the optimistic trajectory of self-evaluation bias. This result confirms that parents who have high levels self-efficacy and academic aspirations for their children promote positive self-efficacy beliefs, regardless of their children's actual academic ability (Bandura et al., 1996). This finding may also suggest that the more parents doubt about their capacity to support their children, the more children perceive that they themselves lack the capacity to succeed at school. Altogether, these findings corroborate the significant role of parents in shaping the academic trajectories of their children. 


\section{Outcomes of Children's Optimistic, Realistic or Pessimistic Academic Competence}

\section{Bias}

Our results also reveal that the trajectories of academic bias lead to real-life outcomes, such as school achievement and persistence until the end of secondary school. At equivalent cognitive ability, the present results confirm the long-term benefit for pupils in belonging to the Optimistic trajectory, followed by the Realistic trajectory. In terms of achievement, children in the Optimistic trajectory (and to a lesser extent, Realistic children) had significantly higher teacher-rated achievement scores than children in the Pessimistic trajectory. This finding challenges the assumption that Optimistic children may suffer from their positive bias later in the academic path. It is possible that the positive bias seen in middle childhood acts as a selffulfilling prophecy. That is, Optimistic children in primary school may be increasingly more prone to perceive academic difficulties as challenges and to make external attributions to failures, that increase their engagement, and ultimately school achievement (Bandura, 1993). Although the feedback loops between SEB, engagement, and achievement, has not been investigated in the present study, we have found that the bias of Optimistic pupils steadily increases from primary to secondary school, and that it leads to more positive academic outcomes. This suggests that such feedback loop might exist. Thus, the present results support Taylor and Brown's (1988) theory of positive illusions and corroborate the academic advantages of having an Optimistic bias of academic competence in the long run (Bouffard et al., 2011; Taylor \& Brown, 1988; Wright, 2000).

Our results also reveal that the long-term benefits of belonging to an Optimistic trajectory of SEB can be generalized to academic persistence. Optimistic pupils were almost eight times more likely to want to go to university as compared with the Pessimistic pupils, and three times 
more likely to do so as compared with Realistic pupils. The advantages of belonging to a Realistic trajectory of SEB were mixed. That is, Realistic students scored lower than Optimistic students on all the persistence variables. These results somewhat challenge the realistic view of SEB (e.g., Colvin et al., 1995). This view posits that being realistic about oneself should lead to an overall better adjustment. Realistic students in the present study were significantly more adjusted than Pessimistic students in terms of their attitudes towards dropout, their level of persistence until the end of secondary school, and were more likely to envision going to university than were their Pessimistic counterparts. All in all, our results show that, although Realistic students are generally better adjusted than Pessimistic students, their levels of achievement and persistence are significantly lower than those of the Optimistic students.

In sum, an important finding that emerges from the current study is that a unique and substantial portion of achievement and behavioral persistence of students arose from selfenhancing their own academic capacities. Consistent with past research (e.g., Bouffard et al., 2011; Wright, 2000), students with a positively biased trajectory of self-evaluation are those who have the greatest academic benefits. Future research should shed light on the psychological correlates that foster an optimistic trajectory of SEB.

\section{Implications}

Our perspective highlights the importance of evaluating how perceptions of competence at school differ from real cognitive abilities. This study has practical implications in school contexts, especially for pupils who underestimate their competence. The negative impact of belonging to a Pessimistic trajectory of self-evaluation bias in the middle of primary school is pervasive until the end of secondary school. Such a negative bias is associated with less adaptive parenting styles, and academic achievement and persistence. Teachers, school psychologists, and 
the more general school environment should be particularly careful to find techniques to engage with these children in ways that promote a greater sense of competence, irrespective of the objective ability. In line with the incremental and entity implicit theories of intelligence (Dweck \& Leggett, 1988), a simple way for teachers and school psychologists to promote pupils’ competence at school would be to foster growth mindsets in the classroom. Children's beliefs that their intelligence is malleable and can be developed through hard work (incremental theory), have been associated with greater motivation, school engagement and achievement (Rattan, Good, \& Dweck, 2012). Rattan, et al. (2012) have shown that school teachers play an important role in improving pupils' growth mindsets (incremental theory). Teachers who themselves believe that intelligence is static are more likely to think that poor grades are due to poor intelligence, and are more likely to adopt "soft" approaches to failures, such as lowering standards for their pupils and giving them less work (Rattan et al., 2012). Teachers also affect their pupils' own perception of competence and implicit beliefs through intelligence praise (that fosters entity beliefs) or hard work praise (that is linked with incremental beliefs, Mueller \& Dweck, 1998). Intervention studies can be implemented with teachers, or directly with pupils, to promote growth mindsets at school. Such interventions have been successful in increasing students' motivation and achievement in school contexts (Blackwell, Trzesniewski, \& Dweck, 2007; Rattan et al., 2012). School psychologists are in a unique position to help implement these interventions. Aligned with the results of the present study, interventions to increase growth mindsets are likely to decrease the negative biases of SEB of pessimistic students.

\section{Limitations and Future Research}

The current study has some limitations, and these highlight some areas for future research. First, we mostly relied on questionnaire data to assess the measures used in this study. 
Fortunately, these measures came from different sources including the pupils themselves, objective and validated measures of cognitive ability, and external measures taken from teachers and parents. In addition, the present longitudinal study spanned nine years and thus attrition was to be expected. The attrition rate was consistent with those reported in past research involving similar populations, but attrition restricts generalizability. Also, the person-centered analysis we used had many benefits, including the natural separation of pupils into different classes according to their own trajectories, but this type of analysis may also limit the generalizability of the present results. Future research is needed to replicate our findings on the latent trajectories of competence bias. Furthermore, our choice of covariates was based on parenting variables. Including more environmental factors in future research could provide a broader picture of the determinants of self-evaluation bias. Our research is unique as it is the first to find that the three broader categories of biases found in past research occur naturally in a population of children. However, the mechanisms underlying the directions of the trajectories are still to be uncovered. In this respect, an important area for future research concerns the feedback loop between SEB and academic outcomes. Measuring parenting predictors, cognitive ability, and outcomes at each time of measurement should help reveal these underlying mechanisms. Although we found that Optimistic students were advantaged in terms of academic outcomes, it is possible that they socially suffer from their positive illusions. Future research should investigate the social consequences of having biases in self-perceptions of academic competence in childhood and adolescence. Finally, an interesting avenue for future research is to implement intervention studies and randomized control trials that would uncover effective strategies to overcome the negative bias of the subpopulation of pessimistic children.

\section{Conclusion}


The present research contributes to the ongoing debate about the consequences of having illusory biases of academic competence by thoroughly examining the correlates, developmental trajectories, and consequences of these biases in school contexts. While models that put forward the benefits of either positive or realistic self-evaluation biases (Colvin et al., 1995; Taylor \& Brown, 1988) have shown mixed results, our study clearly demonstrates the overwhelming benefit of having positive self-evaluation biases at school. This study also shows the advantages of assessing biases in perceptions of competence, i.e. the extent to which pupils believe that their competence is disproportionate as compared with their objective cognitive ability. Amongst these advantages, we have established that these biases can increase or decrease over time, and that these trajectories are associated with very distinct parenting correlates and academic outcomes.

In conclusion, many educators still consider that an overestimated self-evaluation of competence leads to long-term negative consequences and that these students should be more realistic. Evidence from our study demonstrates that, even after nine years, children with an enduring optimistic view of their competence benefit the most from their self-evaluation biases. 


\section{References}

Ardelt, M., \& Eccles, J. S. (2001). Effects of mothers' parental efficacy beliefs and promotive parenting strategies on inner-city youth. Journal of Family Issues, 22, 944-972. doi:10.1177/019251301022008001

Aunola, K., Stattin, H., \& Nurmi, J. E. (2000). Parenting styles and adolescents' achievement strategies. Journal of Adolescence, 23, 205-222. doi:10.1006/jado.2000.0308

Bandura, A. (1986). Social Foundations of Thought and Action: A Social Cognitive theory. Englewood Cliffs, NJ: Prentice-Hall.

Bandura, A. (1993). Perceived self-efficacy in cognitive development and functioning. Educational Psychologist, 28, 117-148.

Bandura, A. (1997). Self-efficacy: The exercise of control. New York: Freeman.

Bandura, A., Barbaranelli, C., Caprara, G. V, \& Pastorelli, C. (1996). Multifaceted impact of self-efficacy beliefs on academic functioning. Child Development, 67, 1206-1222. doi: $10.2307 / 1131888$

Baumeister, R. F. (1989). The optimal margin of illusion. Journal of Social and Clinical Psychology. doi:10.1521/jscp.1989.8.2.176

Baumrind, D. (1971). Current patterns of parental authority. Developmental Psychology, 4, 1103.

Baumrind, D. (1991). Parenting styles and adolescent development. In J. Brooks-Gunn \& A. C. Lerner, R., and Peterson (Eds.), The encyclopedia of adolescence (pp. 2, 746-758). New York: Garland.

Blackwell, L. S., Trzesniewski, K. H., \& Dweck, C. S. (2007). Implicit theories of intelligence predict achievement across an adolescent transition: A longitudinal study and an 
intervention. Child Development, 78, 246-263. doi:10.1111/j.1467-8624.2007.00995.x

Boissicat, N., Pansu, P., Bouffard, T., \& Cottin, F. (2012). Relation between perceived scholastic competence and social comparison mechanisms among elementary school children. Social Psychology of Education, 15, 603-614. doi:10.1007/s11218-012-9189-z

Bong, M., Cho, C., Ahn, H. S., \& Kim, H. J. (2012). Comparison of self-beliefs for predicting student motivation and achievement. Journal of Educational Research, 105, 336-352. doi:10.1080/00220671.2011.627401

Bong, M., \& Clark, R. E. (1999). Comparison between self-concept and self-efficacy in academic motivation research. Educational Psychologist, 34, 139-153. doi:10.1207/s15326985ep3403_1

Bouffard, T., Boisvert, M., \& Vezeau, C. (2002). The illusion of incompetence and its correlates among elementary school children and their parents. Learning and Individual Differences, 14, 31-46. doi:10.1016/j.lindif.2003.07.001

Bouffard, T., Marcoux, M.-F., Vezeau, C., \& Bordeleau, L. (2003). Changes in self-perceptions of competence and intrinsic motivation among elementary schoolchildren. British Journal of Educational Psychology, 73, 171-186. doi:10.1348/00070990360626921

Bouffard, T., Markovits, H., Vezeau, C., Boisvert, M., \& Dumas, C. (1998). The relation between accuracy of self-perception and cognitive development. British Journal of Educational Psychology, 68, 321-330.

Bouffard, T., Roy, M., \& Vezeau, C. (2005). Self-perceptions, temperament, socioemotional adjustment and the perceptions of parental support of chronically underachieving children. International Journal of Educational Research, 43, 215-235. doi:10.1016/j.ijer.2006.06.003 Bouffard, T., Vezeau, C., Roy, M., \& Lengelé, A. (2011). Stability of biases in self-evaluation 
and relations to well-being among elementary school children. International Journal of Educational Research, 50, 221-229. doi:10.1016/j.ijer.2011.08.003

Brand, S., Hatzinger, M., Beck, J., \& Holsboer-Trachsler, E. (2009). Perceived parenting styles, personality traits and sleep patterns in adolescents. Journal of Adolescence, 32, 1189-1207. doi:10.1016/j.adolescence.2009.01.010

Choi, N., Chang, M., Kim, S., \& Reio, T. G. (2015). A structural model of parent involvement with demographic and academic variables. Psychology in the Schools, 52, 154-167. doi:10.1002/pits.21813

Cole, D. A., Martin, J. M., Peeke, L. A., Seroczynski, A. D., \& Fier, J. (1999). Children’s overand underestimation of academic competence: A longitudinal study of gender differences, depression, and anxiety. Child Development, 70, 459-473. doi:10.1111/1467-8624.00033

Coleman, P. K., \& Karraker, K. H. (1998). Self-efficacy and parenting quality: Findings and future applications. Developmental Review, 18, 47-85. doi:10.1006/drev.1997.0448

Coleman, P. K., \& Karraker, K. H. (2000). Parenting self-efficacy among mothers of school-age children: Conceptualization, measurement, and correlates. Family Relations, 49, 13-24.

Colvin, C. R., Block, J., \& Funder, D. C. (1995). Overly positive self-evaluations and personality: Negative implications for mental health. Journal of Personality and Social Psychology, 68, 1152-1162. doi:10.1037/0022-3514.68.6.1152

Connell, J. P., \& Ilardi, B. C. (1987). Self-system concomitants of discrepancies between children's and teachers' evaluations of academic competence. Child Development, 58 , 1297-1307. doi:http://dx.doi.org/10.2307/1130622

Côté, S., Bouffard, T., \& Vezeau, C. (2014). The mediating effect of self-evaluation bias of competence on the relationship between parental emotional support and children's academic 
functioning. British Journal of Educational Psychology, 8, 415-434.

doi:10.1111/bjep.12045

Deary, I. J., Whalley, L. J., Lemmon, H., Crawford, J. R., \& Starr, J. M. (2000). The stability of individual differences in mental ability from childhood to old age: Follow-up of the 1932 Scottish mental survey. Intelligence, 28, 49-55. doi:10.1016/S0160-2896(99)00031-8

Dornbusch, S. M., Ritter, P. L., Leiderman, P. H., Roberts, D. F., \& Fraleigh, M. J. (1987). The relation of parenting style to adolescent school performance. Child Development, 58, 12441257. doi:10.2307/1130618

Dupeyrat, C., Escribe, C., Huet, N., \& Régner, I. (2011). Positive biases in self-assessment of mathematics competence, achievement goals, and mathematics performance. International Journal of Educational Research, 50, 241-250. doi:10.1016/j.ijer.2011.08.005

Dweck, C. S., \& Leggett, E. L. (1988). A social-cognitive approach to motivation and personality. Psychological Review, 95, 256-273. doi:10.1037/0033-295X.95.2.256

Fan, W., \& Williams, C. M. (2010). The effects of parental involvement on students' academic self- efficacy, engagement and intrinsic motivation. Educational Psychology, 30, 53-74. doi:10.1080/01443410903353302

Galand, B. (2001). Nature and Factors of Violence in Schools. Université Catholique de Louvain.

Gonida, E. N., \& Leondari, A. (2011). Patterns of motivation among adolescents with biased and accurate self-efficacy beliefs. International Journal of Educational Research, 50, 209-220. doi:10.1016/j.ijer.2011.08.002

Gonzalez, A. R., Doan Holbein, M. F., \& Quilter, S. (2002). High school students' goal orientations and their relationship to perceived parenting styles. Contemporary Educational 
Psychology, 27, 450-470. doi:10.1006/ceps.2001.1104

Gramzow, R. H., Elliot, A. J., Asher, E., \& McGregor, H. A. (2003). Self-evaluation bias and academic performance: Some ways and some reasons why. Journal of Research in Personality, 37, 41-61. doi:10.1016/S0092-6566(02)00535-4

Gresham, F. M., Lane, K. L., MacMillan, D. L., Bocian, K. M., \& Ward, S. L. (2000). Effects of positive and negative illusory biases: Comparisons across social and academic self-concept domains. Journal of School Psychology, 38, 151-175.

Hart, C. H., Newell, L., \& Olsen, S. (2003). Parenting skills and social-communicative competence in childhood. In J. O. Greene \& B. R. Burleson (Eds.), Handbook of Communication and Social Interaction Skills (pp. 753-797). Mahwah, NJ: Lawrence Erlbaum Associates.

Hartman, J. D., Patock-peckham, J. A., Corbin, W. R., Gates, J. R., Leeman, R. F., Luk, J. W., \& King, K. M. (2015). Direct and indirect links between parenting styles, self-concealment (secrets), impaired control over drinking and alcohol-related outcomes. Addictive Behaviors, 40, 102-108. doi:10.1016/j.addbeh.2014.08.009

Hoover-Dempsey, K. V., Bassler, O. C., \& Brissie, J. S. (1992). Explorations in parent-school relations. The Journal of Educational Research, 85, 287-294. doi:10.1080/00220671.1992.9941128

Ice, C. L., \& Hoover-Dempsey, K. V. (2011). Linking parental motivations for involvement and student proximal achievement outcomes in homeschooling and public schooling settings. Education and Urban Society, 43, 339-369. doi:10.1177/0013124510380418

Jacobs, J. E., Lanza, S., Osgood, D. W., Eccles, J. S., \& Wigfield, A. (2002). Changes in children's self-competence and values: Gender and domain differences across grades one 
through twelve. Child Development, 73, 509-527. doi:10.1111/1467-8624.00421

Jones, T. L., \& Prinz, R. J. (2005). Potential roles of parental self-efficacy in parent and child adjustment: A review. Clinical Psychology Review, 25, 341-363.

doi:10.1016/j.cpr.2004.12.004

Jung, T., \& Wickrama, K. (2008). An introduction to latent class growth analysis and growth mixture modeling. Social and Personality Psychology Compass, 2, 302-317. doi:10.1111/j.1751-9004.2007.00054.x

Kim, M. (2014). Family background, students' academic self-efficacy, and students' career and life success expectations. International Journal for the Advancement of Counselling, 36, 395-407. doi:10.1007/s10447-014-9216-1

Kurman, J. (2006). Self-enhancement, self-regulation and self-improvement following failures. British Journal of Social Psychology, 45, 339-356. doi:10.1348/014466605X42912

Masud, H., Thurasamy, R., \& Ahmad, M. S. (2015). Parenting styles and academic achievement of young adolescents: A systematic literature review. Quality \& Quantity, 49, 2411-2433. doi:10.1007/s11135-014-0120-x

Mueller, C. M., \& Dweck, C. S. (1998). Praise for intelligence can undermine children's motivation and performance. Journal of Personality and Social Psychology, 75, 33-52.

Muthén, B. O. (2002). Beyond SEM: General latent variable modeling. Behaviormetrika, 29, 81117. doi: $10.2333 /$ bhmk.29.81

Muthén, L. K., \& Muthén, B. O. (2010). Mplus Version 7.3. Los Angeles: Muthén \& Muthén. Narciss, S., Koerndle, H., \& Dresel, M. (2011). Self-evaluation accuracy and satisfaction with performance: Are there affective costs or benefits of positive self-evaluation bias? International Journal of Educational Research, 50, 230-240. doi:10.1016/j.ijer.2011.08.004 
Nicholls, J. G. (1978). The development of the concepts of effort and ability, perception of academic attainment, and the understanding that difficult tasks require more ability. Child Development, 49, 800-814. doi:10.2307/1128250

Pinquart, M. (2015). Associations of parenting styles and dimensions with academic achievement in children and adolescents: A meta-analysis. Educational Psychology Review, 1-19. doi:10.1007/s10648-015-9338-y

Pong, S. -1., Johnston, J., \& Chen, V. (2010). Authoritarian parenting and Asian adolescent school performance: Insights from the US and Taiwan. International Journal of Behavioral Development, 34, 62-72. doi:10.1177/0165025409345073

Rattan, A., Good, C., \& Dweck, C. S. (2012). "It's ok - Not everyone can be good at math": Instructors with an entity theory comfort (and demotivate) students. Journal of Experimental Social Psychology, 48, 731-737. doi:10.1016/j.jesp.2011.12.012

Robinson, C. C., Mandleco, B., Olsen, S. F., \& Hart, C. H. (1995). Authoritative, authoritarian, and permissive parenting practices: Development of a new measure. Psychological Reports, 77, 819-830. doi:10.2466/pr0.1995.77.3.819

School Disadvantage Index [Indices de défavorisation par école]. (2005). Retrieved from http://www.education.gouv.qc.ca/fileadmin/site_web/documents/PSG/statistiques_info_deci sionnelle/Ensemble_Indices_05-06.pdf

Spera, C. (2005). A Review of the relationship among parenting practices, parenting styles, and adolescent school achievement. Educational Psychology Review, 17, 125-146. doi:10.1007/s10648-005-3950-1

Steca, P., Bassi, M., Caprara, G. V., \& Fave, A. D. (2011). Parents's self-efficacy beliefs and their children's psychosocial adaptation during adolescence. Journal of Youth and Adolescence, 
40, 320-331. doi:10.1007/s10964-010-9514-9

Steinberg, L., Lamborn, S. D., Darling, N., Mounts, N. S., \& Dornbusch, S. M. (1994). Overtime changes in adjustment and competence among adolescents from authoritative, authoritarian, indulgent, and neglectful families. Child Development, 65, 754-770. doi: $10.2307 / 1131416$

Stull, J. (2013). Family socioeconomic status, parent expectations, and a child's achievement. Research in Education, 90, 53-67. doi:10.7227/RIE.90.1.4

Taylor, S. E., \& Brown, J. D. (1988). Illusion and well-being: a social psychological perspective on mental health. Psychological Bulletin, 103, 193-210. doi:10.1037/0033-2909.103.2.193

Wiederkehr, V., Darnon, C., Chazal, S., Guimond, S., \& Martinot, D. (2015). From social class to self-efficacy: Internalization of low social status pupils' school performance. Social Psychology of Education, 18, 769-784. doi:10.1007/s11218-015-9308-8

Wigfield, A., \& Eccles, J. S. (2000). Expectancy-value theory of achievement motivation. Contemporary Educational Psychology, 25, 68-81. doi:10.1006/ceps.1999.1015

Wolfradt, U., Hempel, S., \& Miles, J. N. V. (2003). Perceived parenting styles, depersonalisation, anxiety and coping bahaviour in adolescents. Personality and Individual Differences, 34, 521-532. doi:10.1016/S0191-8869(02)00092-2

Wright, S. S. (2000). Looking at the self in a rose-colored mirror: Unrealistically positive selfviews and academic performance. Journal of Social and Clinical Psychology, 19, 451-462. doi:10.1521/jscp.2000.19.4.451 
Table 1

Correlation Coefficients Between Self-Evaluation Bias at Six Time Points, their Predictors and Outcomes

\begin{tabular}{|c|c|c|c|c|c|c|c|c|c|c|c|c|c|c|}
\hline & \multicolumn{5}{|c|}{ Self-Evaluation Bias } & \multicolumn{5}{|c|}{ Covariates } & \multicolumn{4}{|c|}{ Outcomes } \\
\hline & 1 & 2 & 3 & 4 & 5 & 6 & 7 & 8 & 9 & 10 & $1 \overline{1}$ & 12 & 13 & 14 \\
\hline 1. SEB T-2 & - & & & & & & & & & & & & & \\
\hline 2. SEB T-3 & $.46^{*}$ & - & & & & & & & & & & & & \\
\hline 3. SEB T-4 & $.38 *$ & $.53 *$ & - & & & & & & & & & & & \\
\hline 4. SEB T-5 & $.41 *$ & $.52 *$ & $.63 *$ & - & & & & & & & & & & \\
\hline 5. SEB T-6 & $.37 *$ & $.43^{*}$ & $.54 *$ & $.66^{*}$ & - & & & & & & & & & \\
\hline 6. SEB T-7 & $.36^{*}$ & $.44^{*}$ & $.51 *$ & $.58 *$ & $.62 *$ & - & & & & & & & & \\
\hline 7. Gender & .05 & -.03 & .02 & .04 & .01 & .07 & - & & & & & & & \\
\hline 8. PR Self-Effi & $.17 *$ & $.24 *$ & $.20 *$ & $.16^{*}$ & $.19 *$ & $.24^{*}$ & .08 & - & & & & & & \\
\hline 9. Authoritar & -.13 & -.08 & -.07 & -.02 & -.02 & -.09 & -.03 & .00 & - & & & & & \\
\hline 10. Authoritat. & $.26^{*}$ & .13 & $.19 *$ & $.16^{*}$ & .11 & $.22 *$ & .08 & .08 & $-.27 *$ & - & & & & \\
\hline 11. TR Ach & $.14^{*}$ & $.21^{*}$ & $.29 *$ & $.28 *$ & $.30 *$ & $.37 *$ & $.25^{*}$ & .13 & .04 & .05 & - & & & \\
\hline 12. Att Drop & $-.18^{*}$ & $-.22 *$ & $-.21 *$ & $-.31 *$ & $-.29 *$ & $-.48 *$ & $-.24 *$ & $-.19 *$ & .09 & -.13 & $-.29 *$ & - & & \\
\hline 13. High Deg & $.17 *$ & $.15^{*}$ & $.16^{*}$ & $.20 *$ & $.20 *$ & $.27 *$ & $.30 *$ & $.15^{*}$ & .03 & .05 & $.35^{*}$ & $-.42 *$ & - & \\
\hline 14. Persis & .06 & .04 & .10 & .11 & .02 & .13 & .10 & .00 & -.01 & .09 & $.17 *$ & $-.30 *$ & $.37 *$ & 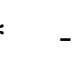 \\
\hline
\end{tabular}

(Continued) 
Table 1. Correlation Coefficients Between Self-Evaluation Bias at Six Time Points, their Predictors and Outcomes (continued)

Note. $\mathrm{N}=711$. Gender coding: $0=$ Male; 1 = Females. Persistence coding: $0=$ Drop-out, $1=$ Persistence. $\mathrm{TR}=\mathrm{Teacher}-\mathrm{Rated}$; PR = Parent-Rated; SEB = Self-Evaluation Bias; PR Self-Effi = Parental Self-Efficacy; Authoritat = Authoritative; Authoritar =

Authoritarian; TR Ach = Teacher-Rated Achievement; High Deg = Highest degree sought; Persis = Persistence; Att Drop = Positive attitudes towards dropout; Gender, Highest Degree Sought, and Persistence are categorical variables. $*=p<.001$. 
Table 2

Model Fit Indices for 1 - 5 Class Solutions of Latent Trajectories of Self-Evaluation Bias

\begin{tabular}{lccccccc}
\hline $\begin{array}{l}\text { Number } \\
\text { of Classes }\end{array}$ & AIC & BIC & SSABIC & Entropy & LMR LRT & VLMR LRT & $\begin{array}{l}\text { Posterior } \\
\text { Probability }\end{array}$ \\
\hline 1 & 8595.95 & 8664.45 & 8616.83 & & & & \\
2 & 8984.97 & 9044.34 & 9003.06 & .73 & $749.26^{* * *}$ & $777.78^{* * * *}$ & $.90 / .93$ \\
$\mathbf{3}$ & $\mathbf{8 7 1 3 . 9 9}$ & $\mathbf{8 7 9 1 . 6 3}$ & $\mathbf{8 7 3 7 . 6 5}$ & $\mathbf{. 7 3}$ & $\mathbf{2 6 8 . 7 5 * * *}$ & $\mathbf{2 7 8 . 9 8 * * *}$ & $\mathbf{. 8 9 / . 8 7 / . 8 8}$ \\
4 & 8650.14 & 8746.04 & 8679.36 & .73 & 71.85 & 69.21 & $.86 / .84 / .82 / .87$ \\
5 & 8617.45 & 8731.64 & 8652.26 & .70 & 39.18 & 40.68 & $.70 / .87 / .81 / .79 / .78$
\end{tabular}

Note. Results from the 1-class model are from the quadratic latent growth model and are presented for information purpose only. Fit information for the retained model is presented in bold typeface. AIC $=$ Akaike Information Criterion; BIC = Bayesian Information Criterion; SSABIC = Sample-Size Adjusted BIC; LMR LRT $=$ Lo-Mendel-Rubin Likelihood Ratio Test; VLMR LRT $=$ Vuong LMR LRT. $*=p<.05, * *=p<.01, * * *=p$ $<.001$. 
Table 3

Results of Gender and Parenting Styles Variables Predicting Latent Trajectory Class Memberships

\begin{tabular}{|c|c|c|c|c|c|c|c|c|c|}
\hline \multirow{3}{*}{$\begin{array}{l}\text { Comparison Group } \\
\text { Assessed Group }\end{array}$} & \multicolumn{3}{|c|}{ Realistic } & \multicolumn{3}{|c|}{ Pessimistic } & \multicolumn{3}{|c|}{ Pessimistic } \\
\hline & \multicolumn{3}{|c|}{ Optimistic } & \multicolumn{3}{|c|}{ Optimistic } & \multicolumn{3}{|c|}{ Realistic } \\
\hline & $\mathrm{B}$ & $S E \mathrm{~B}$ & OR & $\mathrm{B}$ & $S E \mathrm{~B}$ & OR & $\mathrm{B}$ & $S E \mathrm{~B}$ & OR \\
\hline Gender & -0.14 & 0.22 & 0.87 & -0.02 & 0.28 & .97 & .11 & 0.26 & 1.11 \\
\hline Par Self-Effi & $0.67 * *$ & 0.22 & 1.96 & $1.23 * * *$ & 0.26 & 3.42 & $.56^{* *}$ & 0.20 & 1.74 \\
\hline Authoritarian & 0.08 & 0.16 & 1.09 & 0.00 & 0.22 & 1.00 & -.08 & 0.21 & 0.92 \\
\hline Authoritative & $0.49 *$ & 0.21 & 1.64 & $1.11 * * *$ & 0.23 & 3.03 & $.61 * * *$ & 0.18 & 1.85 \\
\hline
\end{tabular}


Running head: TRAJECTORIES OF SELF-EVALUATION BIAS

Table 4

Mean Scores and Proportions of the Achievement and Persistence Outcomes Across Trajectory

Classes

Latent Trajectory Class

Optimistic

Realistic

Pessimistic

\begin{tabular}{lllll}
\hline Mean & SE (Mean) & Mean & SE (Mean) & Mean \\
\hline
\end{tabular}

1. Achievement measure

TR Achievement (max. 5)

$4.28 \quad .012$

$3.50 \quad .09$

2.76

.16

2. Persistence measures

Att Dropout (max. 4)

$1.52 \quad .04$

$1.85 \quad .04$

2.43

.10

$\%$

SE $(\%)$

$\%$

SE $(\%)$

$\%$

SE $(\%)$

Highest degree sought

Secondary School

$3.9 \quad 2.1$

$14.4 \quad 2.6$

33.4

6.3

Technical College

16.7

3.3

29.9

3.1

33.7

5.8

University

$79.5 \quad 3.8$

$55.7 \quad 3.6$

32.9

6.1

Persistence

Dropout

11.5

3.7

17.7

3.4

28.8

7.4

Persistence

88.5

3.7

82.3

3.4

71.2

7.4

Note. $N=711$. Var. $=$ Variable; $\mathrm{SE}=$ Standard Error; $\mathrm{TR}=$ Teacher-Rated; Att Dropout $=$ Positive attitudes towards dropout.

Highest Degree Sought and Persistence are categorical variables. 
Figure 1. Latent Growth Trajectories of Self-Evaluation Bias of Academic Competence.

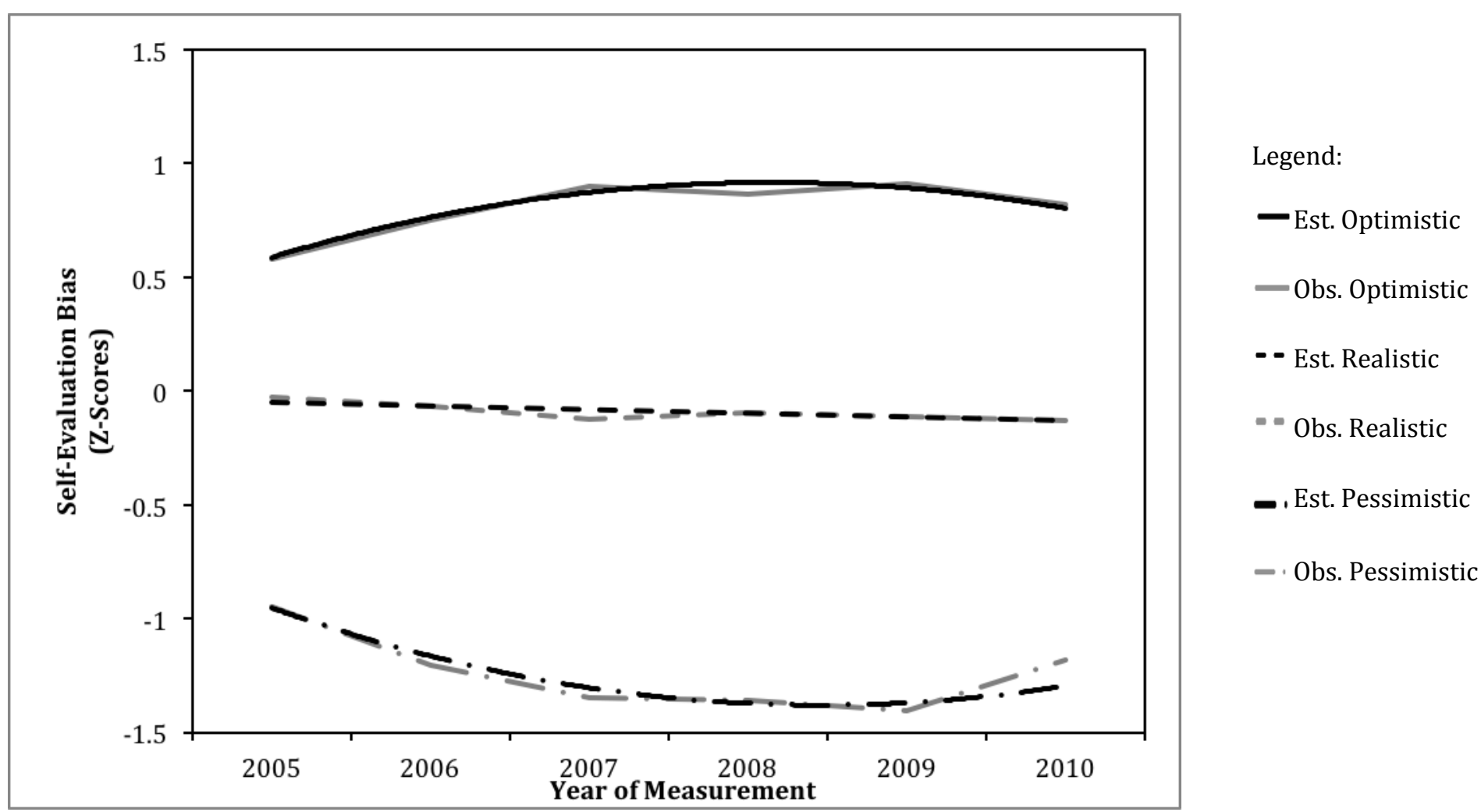

Figure 1. Results are from the unconditional model. Est. = Estimated growth trajectory; Obs. = Observed growth trajectory. Estimated membership probability for the three classes: Optimistic $=27.9 \%$, Realistic $=55.4 \%$, Pessimistic $=16.7 \%$. 